\title{
ASSOCIATION BETWEEN BODY MASS INDEX AND DENTAL CARIES EXPERIENCE IN A GROUP OF EGYPTIAN OBESE CHILDREN (6-12 YEARS OF AGE ). A CASE CONTROL STUDY
}

\author{
Manal Ahmed El Sayed* and Shereen Abd El Ghaffar **
}

\begin{abstract}
Background: Obesity and dental caries are considered as epidemics affecting children's health and wellbeing, they share common etiologic factors as poor dietary habits and wrong life style. Objectives: This study was carried out to assess the correlation between body mass index (BMI) and dental caries experience in a group of obese children as well as to compare them with a group of normal body weight children.
\end{abstract}

Methodology: 180 males and females (6-12 years old) children participated in this study, 90 of them were obese with BMI $>30$ (study group) and 90 were of normal body weight with BMI 18.5-<25 (control group). Caries prevalence for primary and permanent teeth was recorded and compared for both groups. Also, the correlation coefficient between dental caries experience (def and DMF) and BMI was assessed.

Results: Caries prevalence was found to be $88.89 \%$ for the control group versus $51.11 \%$ for

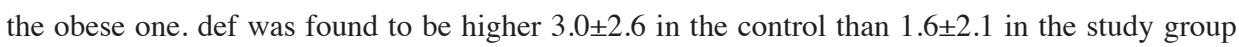
at $\mathrm{p}$ value $\leq 0.001$, while no statistically significant difference was found in the mean DMF in both groups. The results showed that high percentages of children in both groups were breast fed (73.3\% and $70.0 \%$ ) in the control and obese groups respectively. Family history of obesity was found to be $42.2 \%$ of the total number of obese children. The results showed a statistically significant negative correlation between def and birth weight after studying both groups together $(\mathrm{r}=-0.377$ and $\mathrm{p}$ value $\leq 0.001)$.

Conclusion: Caries prevalence recorded a higher level in the control compared to the study group. The mean def was significantly higher in the control than in the study group. No correlation was found between BMI and dental caries in both groups.

KEY WORDS: Obesity, BMI, Dental Caries, Children

* Associate Professor of Pediatric Dentistry, Faculty of Dentistry, Cairo University.

** Professor of Pediatrics, Faculty of Medicine, Cairo University. 


\section{INTRODUCTION}

Obesity is an increasing health threatening condition and is considered a physical, psychological and financial burden on the obese individuals and their communities as well. It is now categorized as an epidemic, and considered as the fifth cause of death worldwide ${ }^{(1,2,3)}$.

WHO Report (2018) stated that the prevalence of obesity tripled since 1975 and 2016 . ${ }^{(4)}$

Obesity is a harmful increase in body weight due to imbalance between energy intake and utilization. The American Academy of Pediatrics Committee on Nutrition reported that obesity is the most prevalent chronic health condition among pediatric population ${ }^{(5)}$. It occurs as a result of interaction between several factors as genetics, environmental, cultural, behavioral and socioeconomic factors ${ }^{\left({ }^{6}\right)}$.

Obese individuals usually suffer from certain life threatening diseases as hypertension, coronary heart diseases, type II diabetes, osteoarthritis, certain types of cancer, sleep apnea and asthma. In general they suffer a very poor quality of life ${ }^{(4,7,8)}$. Obese children may suffer serious psychic problems as low self- esteem, bullying at school, depression and even social isolation ${ }^{(9,10)}$.

Over consumption of caloric dense food is the main factor influencing the incidence of obesity, food industry is a big profitable business nowadays and companies are highly successful in marketing and advertising their products irrespective of high caloric or high fat content. Low practice of exercise together with the use of technology even in playing are among these factors influencing obesity ${ }^{(11,12)}$.

Childhood is a very critical stage of life at which children accept most of their dietary as well as general and oral health related habits which in fact are so difficult to be changed later during adulthood $^{(12)}$

Body Mass Index ( BMI ) is an index used to measure height for weight, it is considered as an indicator of the nutritional status and used to classify individuals into 4 groups according to WHO criteria $2004^{(13)}$.

- $\quad$ Under weight with BMI less than 18.5

- $\quad$ Normal weight with BMI from 18.5 to 24.99

- Over weight with BMI from 25 to less than 30

- Obese with BMI greater than 30

In Egypt , El Shafei et, al 2014 found that the prevalence of obesity and over weight among primary school children from 6 to 11 years old was $9 \%$ in Alexandria governorate and it was more prevalent in females than males ${ }^{(14)}$.

Another study by Hadhood et, al 2017 was conducted on 711 children of an age range from 6 to 14 years old children in Sohag governorate, the authors found that the prevalence of obesity was $14.6 \%$ and 16.5 were overweight ${ }^{(15)}$.

Additionally, Salama and Tayel 2018 found that the prevalence of obesity and overweight among preschool children in Alexandria were 23\% and $14 \%$ respectively .while $6 \%$ were under weight and $57 \%$ of the screened children were of normal body weight $^{(16)}$.

Both obesity and dental caries are multifactorial diseases and sharing the same etiological factors as poor dietary habits, excessive intake of carbohydrates, frequent intake of sugary snacks and soda beverages $^{(17-19)}$.

Both diseases occur as a result of malnutrition which has a great effect on dental as well as general health pre and post eruptively ${ }^{(18)}$.

Several studies ${ }^{(20-23)}$ had been conducted to assess the correlation between dental caries experience and obesity, the results were contradictory. So the authors decided to conduct this study aiming to throw light on this correlation as well as to compare obese and normal body weight children regarding caries experience. 
The hypothesis in this study is: the obese children will have dental caries experience more than children of normal body weight.

\section{SUBJECTS \& METHODS}

180 children participated in this study, 90 of them were obese with BMI $>30$ and 90 were of normal body weight with BMI from 18-<25.

After preparing the proposal and before starting conduction of tis study, an ethical approval was obtained from the Ethical committee of the Faculty of Dentistry, Cairo University.

\section{Power of the study}

Group sample sizes of 90 in Control and 90 in Obese group achieve $99.990 \%$ power to detect a difference between the group proportions of 0.3780 . The proportion in obese group is assumed to be 0.4330 under the null hypothesis and 0.8110 under the alternative hypothesis. The proportion in the control group is 0.4330 . The test statistic used is the two-sided Z-Test with unpoled variance. The significance level of the test is $0.0500^{(24)}$.

A total of 180 children participated in this study 90 of them were diagnosed as obese (study group), all of them were chosen from the Obesity clinic, Endocrinology department, Abou El Rich children's Hospital, Faculty of Medicine, Cairo University.

\section{Inclusion criteria for obese group:}

1- All of them were diagnosed as obese with BMI greater than 30 (according to data from children's diagnostic files).

2- All of them were non- syndromic, obesity was not related to any hormonal dysfunction nor to any syndromes or medically compromising conditions as hypothyroidism, diabetes mellitus that may alter growth pattern or body weight .

3- Children whom their parents approved to participate in the study.
An informed consent was obtained from the parents as an approval to make their children participate in this study.

The control group included 90 children of the same age range and were chosen from the Pediatric Dentistry Department, Faculty of Dentistry, Cairo University as non-symptomatic and attended to the department complaining extrinsic stain or esthetic problems and seeking orthodontic referral .

\section{Inclusion criteria for control group:}

1- Children of normal body weight with BMI between $18.5-<25$.

2- Apparently healthy Children.

3- All of them were non-symptomatic and did not complain any pain due to dental caries.

4- Children whom their parents approved to participate in the study.

BMI was calculated for the control group by using a digital scale $(150 \mathrm{~kg}$.) to measure the weight and (200 cm. tape) to measure the height according to WHO guidelines (2004) ${ }^{(13)}$ as follow :

$$
\mathrm{BMI}=\text { weight }(\mathrm{kg}) / \text { height }\left(\mathrm{m}^{2}\right)
$$

\section{Assessment of dental caries:}

Children of both groups were clinically examined for caries experience using def index for primary teeth and DMF index for permanent teeth.

Dental caries was evaluated according to WHO criteria (1997) visually up to the cavitation level. ${ }^{(25)}$

Teeth were examined under a source of natural (day) light near a window. Dental examination was conducted to detect pits and fissures caries as well as the obvious cavitated proximal caries.

Caries indices were recorded for each child individually, def for primary teeth and DMF for 
permanent teeth; then these indices were calculated for the whole group.

\section{Statistical analysis:}

Data presented as mean, standard deviation (SD), frequency and percentage when appropriate. Independent t-test used to compare between tested groups for the mean birth weight, BMI,and caries experience, Chi-square test used to compare between tested groups for prevalence of def and DMF.

Spearman rho correlation coefficient used to correlate def, DMF, type of feeding, birth weight and BMI $(\alpha=0.05)$.

Statistical analysis was performed with IBM® SPSS ${ }^{\circledR}$ (IBM Corp. Released 2017. IBM SPSS Statistics for Windows, Version 25.0. Armonk, NY: IBM Corp) ${ }^{(26)}$

\section{RESULTS}

\section{Descriptive results:}

All children participated in this study were of an age ranged between 6-12 years with a mean of $9.2 \pm 1.5$ and $8.8 \pm 1.7$ years in the control and obese groups respectively with non-significant difference. Both sexes were involved in both groups and equally represented in the control (50\% for each sex) while $65.6 \%$ were males and $34.4 \%$ were females of the obese group (Table 1).

The results showed that high percentages of children in both groups were breast fed $(73.3 \%$ and $70.0 \%$ ) in the control and obese groups respectively. Family history of obesity was found to be $42.2 \%$ of the total number of obese children. Dental caries experience was $88.89 \%$ in the control group versus $51.11 \%$ of the test group (Table 1 ).

TABLE (1) Demographic data and dental caries experience of both groups

\begin{tabular}{|c|c|c|c|c|c|}
\hline & & Contro & & Obese & \\
\hline & & $\mathrm{n}(90)$ & $\%$ & $\mathrm{n}(90)$ & $\%$ \\
\hline & $\mathrm{F}$ & 45 & $50.0 \%$ & 31 & $34.4 \%$ \\
\hline & M & 45 & $50.0 \%$ & 59 & $65.6 \%$ \\
\hline & Breast & 66 & $73.3 \%$ & 63 & $70.0 \%$ \\
\hline Type of Feeding & Formula & 19 & $21.1 \%$ & 23 & $25.6 \%$ \\
\hline & Mixed & 5 & $5.6 \%$ & 4 & $4.4 \%$ \\
\hline Family history & Negative & - & - & 52 & $57.8 \%$ \\
\hline of obesity & Positive & - & - & 38 & $42.2 \%$ \\
\hline Caries prevalence in primary & Caries Free & 17 & $18.9 \%$ & 51 & $56.7 \%$ \\
\hline teeth (def) & Caries affected & 73 & $81.1 \%$ & 39 & $43.3 \%$ \\
\hline Caries prevalence in permanent & Caries Free & 51 & $56.7 \%$ & 59 & $65.6 \%$ \\
\hline teeth (DMF) & Caries affected & 39 & $43.3 \%$ & 31 & $34.4 \%$ \\
\hline 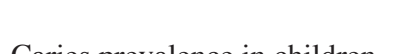 & Caries free & 10 & $11.11 \%$ & 44 & $48.89 \%$ \\
\hline & Caries affected & 80 & $88.89 \%$ & 46 & $51.11 \%$ \\
\hline
\end{tabular}


TABLE (2) Comparison between age, birth weight, BMI and dental caries (def and DMF) in both groups

\begin{tabular}{|c|c|c|c|c|c|c|c|c|c|}
\hline & \multicolumn{4}{|c|}{ Control } & \multicolumn{4}{c|}{ Obese } & \multirow{2}{*}{ p-value } \\
\cline { 2 - 11 } & Mean & SD & Max & Min & Mean & SD & Max & Min & \\
\hline Age & 9.2 & 1.5 & 12.0 & 6.0 & 8.8 & 1.7 & 12.0 & 6.0 & 0.094 NS \\
\hline Birth weight & 3.1 & 0.5 & 4.5 & 1.8 & 3.4 & 0.5 & 5.0 & 2.5 & $\leq 0.001 *$ \\
\hline BMI & 22.0 & 1.6 & 24.5 & 18.7 & 33.6 & 3.1 & 45.0 & 30.0 & $\leq 0.001 *$ \\
\hline def & 3.0 & 2.6 & 14.0 & 0.0 & 1.6 & 2.1 & 8.0 & 0.0 & $\leq 0.001 *$ \\
\hline DMF & 0.9 & 1.4 & 9.0 & 0.0 & 0.9 & 1.3 & 4.0 & 0.0 & 0.575 NS \\
\hline
\end{tabular}

*=Significant, $N S=$ Non-significant

\section{Analytical results:}

A statistically significant difference was found between the control and obese groups regarding the mean birth weight which was $3.1 \pm 0.5$ and $3.4 \pm 0.5$ respectively at $\mathrm{p}$ value $\leq 0.001$. Also BMI was significantly lower $22 \pm 1.6$ in the control than $33.6 \pm 3.1$ in the obese group respectively at $\mathrm{p}$ value $\leq 0.001$. def was found to be significantly higher $3.0 \pm 2.6$ in the control than $1.6 \pm 2.1$ in the obese group at $p$ value $\leq 0.001$. No statistically significant difference was found in the mean DMF in both groups (Table 2, Fig.I).

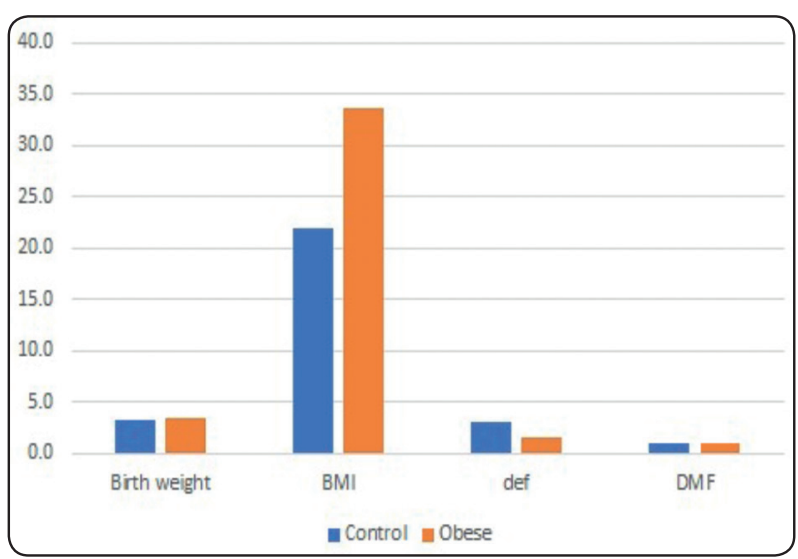

Fig. (I) Bar graph showing the mean values of Birth weight, BMI and def and DMF for both groups.

TABLE (3) Correlation coefficient for def, DMF and type of feeding, birth weight and BMI within each group.

\begin{tabular}{|c|c|c|c|c|c|}
\hline Groups & & & Type of Feeding & Birth weight & BMI \\
\hline \multirow[t]{6}{*}{ Control } & \multirow[t]{3}{*}{ def } & Correlation Coefficient & -.072 & -.192 & -.101 \\
\hline & & Sig. (2-tailed) & $.499 \mathrm{NS}$ & $.070 \mathrm{NS}$ & $.343 \mathrm{NS}$ \\
\hline & & $\mathrm{N}$ & 90 & 90 & 90 \\
\hline & \multirow[t]{3}{*}{ DMF } & Correlation Coefficient & -.069 & -.038 & .039 \\
\hline & & Sig. (2-tailed) & $.520 \mathrm{NS}$ & $.722 \mathrm{NS}$ & $.712 \mathrm{NS}$ \\
\hline & & $\mathrm{N}$ & 90 & 90 & 90 \\
\hline \multirow[t]{6}{*}{ Obese } & \multirow[t]{3}{*}{ def } & Correlation Coefficient & .064 & -.004 & .032 \\
\hline & & Sig. (2-tailed) & $.548 \mathrm{NS}$ & $.971 \mathrm{NS}$ & $.763 \mathrm{NS}$ \\
\hline & & $\mathrm{N}$ & 90 & 90 & 90 \\
\hline & \multirow[t]{3}{*}{ DMF } & Correlation Coefficient & .013 & -.154 & .031 \\
\hline & & Sig. (2-tailed) & $.904 \mathrm{NS}$ & $.146 \mathrm{NS}$ & $.774 \mathrm{NS}$ \\
\hline & & $\mathrm{N}$ & 90 & 90 & 90 \\
\hline
\end{tabular}


TABLE (4) Correlation coefficient of def and DMF with feeding habits ,birth weight and BMI in both groups together.

\begin{tabular}{rlrrr}
\hline & & Type of Feeding & Birth weight & BMI \\
\hline \multirow{2}{*}{ def } & Correlation Coefficient & -.008 & -.377 & -.111 \\
\cline { 2 - 5 } & Sig. (2-tailed) & $.920 \mathrm{NS}$ & $\leq 0.001^{*}$ & $.141 \mathrm{NS}$ \\
\cline { 2 - 5 } & $\mathrm{N}$ & 180 & 180 & 180 \\
\hline \multirow{2}{*}{ DMF } & Correlation Coefficient & -.031 & -.126 & .029 \\
\cline { 2 - 5 } & Sig. (2-tailed) & $.684 \mathrm{NS}$ & $.092 \mathrm{NS}$ & $.702 \mathrm{NS}$ \\
\cline { 2 - 5 } & $\mathrm{N}$ & 180 & 180 & 180 \\
\hline
\end{tabular}

*=Significant, $N S=$ Non-significant

Regarding the correlation between dental caries (def and DMF) and type of feeding, birth weight, and BMI, for each group separately the results showed that weak, non-significant negative correlations were found between def / DMF and these studied variables (except for DMF and BMI) in the control group. While in the test group ,non significant negative correlation was detected between def / DMF and birth weight only (Table 3 ) .However the results showed a statistically significant negative correlation between def and birth weight after studying both groups together $(\mathrm{r}=-0.377$ and $\mathrm{p}$ value $\leq 0.001$ (Table 4).

\section{DISCUSSION}

As previously reported ,dental caries and obesity are health related epidemics and occur as a result of dramatic changes in the life style and dietary habits since $1990 \mathrm{~s}^{(1,2)}$.

Both conditions have the same risk factors as increasing consumption of carbohydrate and fat rich food as well as steady life style, the use of technology based entertainment,, spending several hours watching $\mathrm{T} \mathrm{V}$ which requires taking frequent snacks rich in sugar ${ }^{(6,11,12)}$.

This study was conducted to answer an important question "Is there an association between dental caries and childhood obesity ?" which are considered risk factors that may affect both dental and general health conditions of the child with the result so many difficult burdens on the child ,the family as well as the community in general.

A total of 180 school children participated in this study, 90 of them were obese (as a test group) and 90 were of normal body weight (as a control group).Males and females were included and all of them were of an age range between $6-12$ years which is a mixed dentition period in order to study the conditions of both primary and permanent teeth, also at this age usually there are either acceptance or changes of certain dietary habits and life style of children ${ }^{(27)}$.

All obese children were selected from the Obesity Clinic, Endocrinology Department, Abou El-Rich Children's Hospital, Faculty of Medicine, Cairo University to be under the same umbrella of medical and therapeutic interference, investigations and follow up from the staff members, as well as under nutritional planning offered to these children. All of them were selected as non-syndromic obese (obesity due to poor dietary habits and mal nutrition) to exclude any medical compromising condition that may alter the findings of this study. All of them were having $\mathrm{BMI}>30$.

Children in the control group were selected from the outpatient clinic of the Pediatric Dentistry Department, Faculty of Dentistry, Cairo University as non-symptomatic and not complaining from 
any dental pain, but they came to the department seeking orthodontic referral or checkup. All of them were of normal body weight with BMI from $18-<25$ and apparently healthy.

Both sexes were equally involved in the control group, $65.6 \%$ of the obese group were males which may indicate that obesity is more prevalent among boys at this age. The highest percentage of all children participated in this study were breast fed (73.3\% and $70.0 \%)$ in the control and obese groups respectively followed by bottle and then breast and bottle feeding (table 1). This result may be due to increasing the awareness of mothers about the benefits of this type of natural feeding as well as it is the cheapest method for feeding their infants. However non significant negative correlation was found between caries experience and breast feeding for both groups (table 4), this study goes in line with Walesca et al 2015(28) and Feldens et al $2018^{(29)}$ in their systematic review with high evidence that breast feeding has a great protective effect on the teeth against dental caries than bottle feeding.

Family history was detected among $42.2 \%$ of the obese children which goes in line with Corica et, al 2018 who explained this result on the basis that maternal obesity has a great genetic effect on developing childhood and pre pubertal obesity due to certain genetic factors ${ }^{(30,31)}$ or due to a great tendency of the obese mothers to over feed their children habitually ${ }^{(32)}$

Surprisingly, $88.89 \%$ and $51.11 \%$ of children were caries affected in the control and test groups respectively (table 1). def was found to be higher in the control than in the study group with a statistically significant difference at $\mathrm{p}$ value $\leq$ 0.001 , while, insignificant statistical difference was found regarding DMF in both groups (table 2). Several studies confirmed this finding ${ }^{(16,33,34)}$ and attributed this result to the efforts given by the mothers of obese children to take care of their dietary items, number of meals / day and snacks to decrease carbohydrates as much as they can which result in low caries experience in the obese children. Another explanation is the multifactorial nature of dental caries, not only the dietary pattern.

No correlation was detected between BMI and caries experience (def and DMF) neither in primary nor permanent teeth for both groups when studied separately (table 3 ) or when studied together (table 4). This finding goes in accordance with several studies ${ }^{(15,35,36,37,38)}$ who explained this result on the basis that, dental caries and obesity are multifactorial diseases with predisposing genetic factors and several environmental conditions, the level of parental education, father's occupation and socio-economic standard of the family.

Others explained that both epidemics are very complex in nature due to multi-factorial etiological background and may be affected by oral hygiene, fluoride availability, salivary factors, oral microflora, genetic and biological factors as well as the availability of dental services. All these mentioned factors may contribute in the process of dental caries ${ }^{(23,39,40)}$.

On the other hand, and based on the findings of this study low caries experience in the obese children may be due to the nutritional educational sessions and diet planning offered by the nutritionist in the obesity clinic -endocrinology department to the obese children and their mothers in each recall visit. These sessions assure to decrease carbohydrate content and sweet snacks from the diet of these children with the result of low caries experience.

In a more recent Systematic review by Sahana et al $2018^{(41)}$ which was conducted between 2005 2016, the authors did not reach an exact opinion or consensus between body mass index and dental caries due to varied associations and complex nature.

On contrary, several studies did not confirm the results of the present study and found a positive correlation between BMI and dental caries ,they explained these correlations on the basis that poor 
quality diet, irregular dietary intake and several snacks are linked to increased caries experience, increased body weight and obesity in addition to changing the life-style and excessive use of technology based entertainment for several hours per day ${ }^{(2,11,12,42)}$.

Finally, all children participated in this study (obese and normal body weight) belonged to families seeking health services for free and concerned about the price of dietary items offered to their children than the quality, so high carbohydrate diet, more cheaper snacks and less proteins, fruits and vegetables are consumed. This gives another explanation that supports the finding of increased caries experience among normal body weight children (who did not receive any educational sessions about proper nutrition and good dietary practices) as the obese population in the current study.

\section{Among the limitations of this study:}

1. The sample size was to some extent small but may be due to the selection criteria especially for the obese children (to find non-syndromic obesity cases), with a bigger sample size the authors may obtain different results .

2. This is a case control study, the authors collected all data at a specific period of time. With a longitudinal study some findings might be different due to any changes in the dietary habits or in the life style of children in general.

\section{CONCLUSIONS}

From the results of this study we can conclude that:

1. Caries prevalence was found to be lower $(51.11 \%)$ in the obese group versus $(88.89 \%)$ in the control group. The mean def was significantly higher in the control $(3 \pm 2.6)$ than

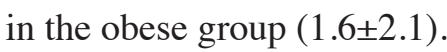

2. No correlation was found between dental carries experience and BMI neither in the obese nor in the normal body weight children.
So, the hypothesis that obesity and dental caries are interrelated as they share nearly the same predisposing factors was not confirmed in this study.

\section{REFERENCES}

1. Tripathi S., kiran K., and Kamala BK. : Relationship between obesity and dental caries in children- A preliminary study. J. OF International Oral Health, 2010,2: 65-72

2. Alm A., Isaksson H. and Fahraeus C.,et al. :BMI status in Swedish children and young adults in relation to caries prevalence. Swed. Dent. J.,2011,35,( 1): 1-8

3. International Association for the Study of Obesity (IASO) 2010 .Obesity: Understanding and challenging the global epidemic 2009-2010 report. http://www.iaso.org/site_ media/uplodes/IASO_Summary_Report_2009.pdf

4. WHO Report about obesity and overweight, Feb. 2018 https://www.who.int/news-room/fact-sheets/detail/ obesity-and- overweight

5. American Academy of Pediatrics: Preventing obesity and eating disorders in adolescents .Pediatrics volume September 2016; 138 (3): e1-e10

6. Daniel SR. and Hassinkk SG.,: Committee on Nutrition. The role of pediatrician in primary prevention of obesity. J. of Pediatrics, 2015,136 (1): e275-e292 www.mdpi.com/ journal nutrients

7. Davis, C. and Carter J.C. : Compulsive over eating as an addiction disorder. A review of theory and evidence. J. of Appetite, 2009,53: 1-8

8. Summerbell, CD., Waters,E., Edmunds, L., Kelly, S., Brown, T. and Campbell, KJ.: Interventions for preventing obesity in children. Cochrane database System Reviews 2011,3.doi:10.1002/14651858.CD001871.pub2.Retrieved from http://online library.wiley.com/doi/10.1002/ 14651858CD001871.pub2/pdfs.

9. Young-Hyman D., Tanofsky-Kraff M., Yaonvski SZ., Keil M., Peyrot M. and Yanovski JA.: Psychological status and weight related distress in over weight or at high risk of over weight children. J. Obesity, Silver Spring 2006,14(12):2249-2258

10. Seo, D. and Sa,J.: A Meta-analysis of obesity intervention among U.S. minority children.Journal of Adolescent Health, 2014,46(4):309-323 
11. Dietz WH. And Gortmaker SL.: Do we fatten our children at the television set? Obesity and television viewing in children and adolescents.Pediatrics,1985,75, 807-812 PubMed.

12. Hassink SG.: Childhood obesity and overview pediatric obesity prevention, intervention, and treatment strategies for primary care. American Academy of Pediatrics,2007,1(6): 22-25

13. WHO,: Obesity: Preventing and Managing The Global Epidemic. report no. 894 , reported in 2000 and reprinted 2004 ,no. of pages 253.

14. El-Shafie,, A.M., Hogran H.H. and Dohein A.M.: Prevalence of obesity in primary school children living in Alexandria governorate. Menoufia Medical Journal, 2014,27: 529-532

15. Hadhood, S.E., Ali R.A., Mohammed M., M. and Mohammed E., S.: Prevalence and correlates of overweight and obesity among school children in Sohag Egypt. Open Access Article, Open Journal of Gastroenterology, 2017, 7: 75-88 available on http://www.scirp.org/journal/ojgas

16. Salama A.A., and Tayel D.: Over weight and obesity among preschool children aged 2-5 years in Alexandria Egypt. Canadian Journal of Clinical Nutrition,2018, 6(1): 34-54

17. Hooley m., Skouteris H., Bouugarin C.,Star J. and Kilpatrick N.: Body mass index and dental caries in children and adolescents : A systematic review of literature from 2004-2011, Systematic Reviews J., 2012, 1(1): 1-26 doi: 10.1186/2046-4053-1-57 PMC Free Article, PubMed, Cross Ref.

18. Costacurta, M., Direnzo, L., Sicuro, S., et,al.: Dental caries and childhood obesity: analysis of food intake, life style, European Journal of Pediatric Dentistry, 2014,15: 343-348

19. Fritas A.R., Aznar F.D., Tinos A.M., et,al.: Association between dental caries activity, quality of life and obesity in Brazilian adolescets, International Dental Journal, 2014, 64 (6): 318-323

20. Sede M.A. and Ehizele A.O.: Relationship between obesity and oral diseases, Nigerian Journal of Clinical Practice, 2014, 17 (6): 683-690.

21. Alukal E., Anzil K.S., Baby M., George E.K., et,al.: Association between body mass index and dental caries among Anganwadi Children of Belgaum City, Indea.j. Contemp. Dent. Pract., 2016,,17 (10): 844-848.

22. Marshall T.A., Julie M., Barbara A. et al.: Dental caries and childhood obesity: role of diet and socioeconomic sta- tus. Community Dent. And Oral Epidemiol. 2007, 35 (66): $449-458$

23. Adri G., Alkillzy M., Feng Y.S. and Splieth C.: Overweight and dental caries: the association among German Children. Int. J. Dent. 2015, 25: 174-182.

24. Faul, F., Erdfelder, E., Lang, A.-G., \& Buchner, A.: G* Power 3: A flexible statistical power analysis program for the social, behavioral, and biomedical sciences. Behavior Research Methods, 2007,39, 175-191.

25. World Health Organization (WHO): Oral Health Surveys. Basic Method, 1997

26. IBM® ${ }^{\circledR}$ SPSS ${ }^{\circledR}$ (IBM Corp. Released 2017. IBM SPSS Statistics for Windows, Version 25.0. Armonk, NY: IBM Corp) .

27. Dr.Hardik Mangukia, Dr. Ruchi Arora and Dr. Dogra: Relationship between body mass index and socioeconomic status in a population of 4-14 year old children in Udaipur city. J. of Dental and Medical Sciences (IOSR-JDMS), March 2017, 16 (3):99-103

28. 28-Walesca MA, Isabela AP. And Carolina CM.: Breast and bottle feeding as risk factors for dental caries: A systematic review and metanalysis. Pub Med search, https:// www.ncbi.nlm.nih.gov/pmc/articles/PMC4651315/plos one $.2015,10(11)$ : e0142922

29. 29-Feldens CA., Rodrigues PH., de, Anastacio G., Vitolo MR. and Chaffee BW.: Feeding frequency in infancy and dental caries in childhood: ,prospective cohort study : A Pub search-Int.Dent. J., April 2018, 68,(2):113-121 .Available on line on : dio:10.1111/idj.12333.Epub.Nov. 2017

30. Corica D., Aversa T,. Valenzise M., Messina MF., Alibrandi A., De Luca F. and Wasnieweska M.: Does family history of obesity, cardiovascular and metabolic diseases influence onset and severity of childhood obesity ? Front. Endocrinol,May 2018,Pub Med search http://www.ncbi. nlm.nih.gov/pubmed/29770124

31. Hu, F., : Genetic predictors of obesity.In: Hu,ed. Obesity Epidemiology, New York City: Oxford University Press, 2008, 437-460

32. Cited from: Hana S. shaheen, 2015,:Obesity Intervention in Egypt: Identifying Gaps and Highlighting Assets. Master Thesis submitted to the department of Sociology, Anthropology, Psychology and Egyptology. American University in Cairo 
33. Sobko T., Svensson V., Ek. A., et,al.: A randomized control trial for over weight and obese parents to prevent childhood obesity. Early Stop. (Stockholm Obesity Prevention Program). BMC Public Health, May 2011,11 (1):336 doi: 10.1186/1471-2458-11-336.1 Reviewed from : http:// www.ncbi.nlm. Nih.gov/pmc /articles/PMC 3121630/.

34. Malek TM.,Wright CM. and Kay J.: Childhood growth and dental caries. Community Dental Health, 2009, 26 (1): 38-42

35. Bafti, LS., Hashemipour, MA,. Poureslamim H. and Hoseinian, Z.: Relationship between body mass index and tooth decay in a population of 3-6 year old children in Iran. Inter. Jour. of Dentistry, 2015 , article ID 126530, 5 pages on http://dx.doi.org/10.1155/2015/126530

36. De Jong Lenters M, Paula van Dommelen, Annemarie A., Schuller, and Erik H.w. Verrips.: Body mass index and dental caries in children aged 5 to 8 years attending adental pediatric referral practice in Netherlands. BMC Research Notes 2015, on http://doi.org/10.1186/s13104-015-1715-6 Open Access Article , CE. Published December 2015

37. Yen CE, and Hu SW.: Association between dental caries and obesity in preschool children. Eur. J. Pediatr. Dent., Sept. 2013,14(3): 185-189

38. Hayden C., BowlerJO., Chambers S., Freeman R., Humphris G., Richards D. and Cecil JE.: Obesity and dental caries in children: A Systematic Review and Meta -analysis. Community Dent. Oral Epidemiol., August 2013, 41(4): 289-308

39. Vallogini G., Nobili V., Rongo R., De Rosa s., Magliarditi F., and Gsleotti A.: Evaluation of the relation-ship between obesity ,dental caries and periodontal diseases in adolescents. European Journal of Pediatric Dentistry, 2017, 18 (4): 268-272

40. Noberg C., Hallstrom SU., Matsson L., Thorngren-Jerneck and Kligberg G/: Body mass index (BMI) and dental caries in 5-year-old children from Southern Sweden. Community Dent. Oral Epidemiol. 2012.40: 315-322

41. SdhbBahuguna R., Kulshresta P. and Jain A.: Relation-ship between body mass index and dental caries prevalenceRole of diet and socioeconomic status .J. Res. Adv. Dent. 2014, 3 (3): 114-124

42. Sahana Shivakumar, Adit Srivastava and Ganiga C Shivakumar.: Body Mass Index and Dental Caries. A Systematic Review. Int. J. Clin Pediatr Dent, 2018,11(3): 228-232

43. Alswat K., Mohammed WS., Wahab MA., and Aboelil AA.: The association between body mass index and dental caries: Cross sectional study. J. Clin. Med Res., 2016 , $8(2): 147-152$ 